\title{
Clinical and functional outcome of metal backed versus all polyethylene post operated total knee replacement patients: a prospective study
}

\author{
Suresh Kriplani, Tejas Patil*, Milind Kulkarni, G. S. Kulkarni, Krishna Kabra, Yash Parikh
}

Department of Orthopaedics, P.G.I. Swasthiyog Pratishthan, Miraj, Maharashtra, India

Received: 03 March 2020

Revised: 29 April 2020

Accepted: 06 May 2020

*Correspondence:

Dr. Tejas Patil,

E-mail: drtejaspatiltpp@gmail.com

Copyright: (c) the author(s), publisher and licensee Medip Academy. This is an open-access article distributed under the terms of the Creative Commons Attribution Non-Commercial License, which permits unrestricted non-commercial use, distribution, and reproduction in any medium, provided the original work is properly cited.

\section{ABSTRACT}

Background: Osteoarthritis (OA) is most common chronic degenerative disease in orthopaedic practice. The literature pertaining to comparison of the clinical outcome and functional outcome between the metal backed and all polyethylene prosthesis for the total knee replacement are scant.

Methods: A prospective study was undertaken in a tertiary hospital April 2018 to June 2019. The final sample size was 32 cases (40 knees) of newly diagnosed of primary OA knee cases treated with cemented TKR with Metal backed prosthesis and 29 cases (40 knees) with all polyethylene prosthesis. The patients were followed up at 1st, 3rd and 6th post-operative months.

Results: Knee clinical score pre-op was not statistically significant. But after 1 month, after 3 months after 6 months, knee clinical score was statistically significant. Knee functional score pre-op, after 1 month, after 3 months, after 6 months was not statistically significant. $87 \%$ patients of metal back total knee replacement and $85 \%$ of all poly total knee replacement had no pain or just mild pain.

Conclusions: Total knee arthroplasty resulted in excellent relief of pain, range of motion, restoration of function, and low prevalence of complications and continues to function well during the follow-up period. Improvement in clinical score in MB group is correlated significantly than all polyethylene group. Knee society scoring system is an effective in evaluating clinical, functional outcomes.

Keywords: Total knee replacement, Polyethylene, Metal backed, Knee clinical score, Knee functional score

\section{INTRODUCTION}

Osteoarthritis is most common chronic degenerative disease in orthopaedic practice. The disease process of osteoarthritis is characterized by the progressive destruction of the articular cartilage, leading to joint space narrowing, subchondral cyst, synovial inflammation and marginal osteophyte formation. ${ }^{1}$

The available reports suggest that almost $13 \%$ of the women and $10 \%$ of the men aged more than 60 year have symptomatic osteoarthritis. The estimates of symptomatic osteoarthritis (OA) are likely to increase due to ageing of the population and the rate of obesity or overweight in the general population. ${ }^{2}$ The studies note that, about $25 \%$ of the people over 55 years may present with the persistent episode of the knee pain. Among them, one in six has to consult their general practitioner about it in a period of one year. About $10 \%$ of the people aged above 55 years have painful disabling knee OA of whom one quarter is severely disabled. $^{3}$

The treatment of OA includes non-pharmacological interventions and surgical interventions such as total knee replacement. The concept of improving knee joint function by modifying the articular surfaces has received attention 
since the $19^{\text {th }}$ century. The surgical techniques have varied from soft tissue interposition arthroplasty to resection arthroplasty to surface replacement arthroplasty. In surface replacement arthroplasty different types of prosthesis were developed to address the complex knee kinematics. ${ }^{4}$

Use of a metal backed base plate has theoretical advantage in that it distributes load more evenly across the implant bone interface that all polyethylene tibia, and thus should decrease the risk of loosening. In addition, as the bearing is modular, the surgeon can select the thickness and constraints of the bearing after the components are fixed However, metal backing reduces the thickness of the polyethylene that can be implanted in the available space, thus increasing the internal stresses within the polyethylene and increasing the risk of wear. The metal backing is more expensive and good medium and longterm result have been reported for the use of non-metal backed components. 5,6

The all polyethylene prosthesis consists of two components. A high-density polyethylene tibial bearing which is placed on the cut surface of the tibia such that it is parallel to the ground and essential at right angles to the long axis of the tibia. This component articulates with a polished, stainless steel femoral component which resembles the natural shape of the distal femur, although sufficiently different as to make both condyles symmetrical. The two components are not linked by any mechanical device and stability of the joint is achieved by a combination of reciprocal shaping of the prosthetic components and surgical techniques that maintain the two components under compressive loading through tension in the surrounding ligaments under compressive loading through tension in the surrounding ligaments and muscles. ${ }^{7}$

Considering the cost saving, all polyethylene tibial components are of potential interest in developing countries like India. The survivorship comparison of all polyethylene and metal backed tibial components in posterior cruciate ligament substituting (PS) total knee arthroplasty (TKA) had not been studied in detail by any studies.

The literature pertaining to comparison of the clinical outcome and functional outcome between the metal backed and all polyethylene prosthesis for the total knee replacement are scant. Hence a prospective study has been undertaken to compare the clinical and functional outcome of metal backed and all polyethylene prosthesis among the patients undergoing total knee replacement.

\section{Aim and objectives}

To study the safety and compare the clinical and functional outcome of the patients undergoing cemented total knee replacement with metal backed and all polyethylene prosthesis.

\section{METHODS}

\section{Study design}

A prospective interventional study was done in the Department of Orthopaedics in Post Graduate Institute of Swasthiyog Pratishthan, Dr G. S. Kulkarni Fracture and Orthopaedic Hospital, Miraj, Maharashtra between April 2018 to June 2019, 40 cases of newly diagnosed cases OA knee treated with cemented TKR with Metal backed prosthesis and 40 cases with all polyethylene prosthesis of all the ages and both sexes, were included in the study after obtaining informed, written and video consent. Clearance from the institutional ethical committee was obtained before starting of the study.

\section{Inclusion criteria}

Inclusion criteria were moderate to severe knee pain, angular knee deformity, knee stiffness (extension lags and flexion contractures) with decreased range of motion, unilateral/bilateral knee involvement, and patients who will give consent for study.

\section{Exclusion criteria}

Exclusion criteria were active infection anywhere in the body, post traumatic/post infection, patient having neurological, psychological, vascular disorder, revision arthroplasty, patients having periprosthetic fracture, and secondary osteoarthritis.

All the patients were subjected for clinical history, thorough physical examination, accurate assessment of the patient's current ambulatory status and need. All the patients planned for TKA were subjected to a multisystem screening protocol to rule out any foci of infection. General condition was assessed with the vital signs and systemic examination. The $\mathrm{Q}$ angles of both knees determined and the valgus cut angle was measured from weight bearing radiographs of the entire limb.

\section{Methods}

All the patients were assessed clinically and functionally using Knee society score. The patients thus selected were divided to two equal groups. Patients were evaluated till end of the follow up, which were not be the case for surgeons and observers performing clinical follow up due to the marked difference in radiographic appearance between implant designs. All patients were operated under combined spinal epidural anaesthesia, tourniquet applied, painting draping done, tourniquet inflated and time noted. Surgeries were performed by 2 experienced surgeons using standardized techniques, using Medial parapatellar approach in all the patients. Both surgeons used standard midline incision and medial parapatellar arthrotomy. Haemostasis was achieved, knee was extended. Patella was everted and knee was flexed with preserving patellar tendon and removed soft tissue and osteophyte that lead to 
soft tissue imbalance and component malposition. Patellar resurfacing was done in all the cases. Bony preparation was done using alignment axes in knee with help of jig for distal femur and proximal tibia by using saw and power drill. Gap balancing was done. Trail of implant was done, stability and range of motion confirmed. For final implantation, pulsatile lavage was used prior to applying bone cement with cemented tibial knee component in all procedures. The tourniquet was released before closure, deflating time was noted and all the bleeding vessels were cauterized. A drain was placed in all the patients. The wound was closed in layers, A sterile Gamgee and bandage dressing was applied to the wound. Postoperative IV antibiotic and DVT prophylaxis was given as per protocol. $\mathrm{X}$-rays AP and lateral views were taken immediate postoperatively. Patients were stimulated to mobilize with immediate full weight bearing. Wound was inspected on $2^{\text {nd }}$ post-operative day, drain was removed after assessing the collection and dry dressings were done on $2^{\text {nd }}$ postoperative day, $5^{\text {th }}$ postoperative day and $9^{\text {th }}$ post-operative day. Sutures were removed on $14^{\text {th }}$ post-operative day.

\section{Follow-up}

The patients were followed up after discharge at the end of 1 month, 3 months and 6 months for assessing clinical and functional parameters.

\section{Statistical analysis}

Obtained data was entered into excel sheet and analyze using SPSS vs 20, chi square test was used, p value of less than 0.05 was statistically significant.

\section{RESULTS}

About $75.8 \%$ of the patients in all polyethylene group and $59.37 \%$ of the patients in metal backed (MB) group belonged to more than 60 years group which was not statistically significant.

Table1: Distribution of the study group according to age.

\begin{tabular}{|lll|}
\hline $\begin{array}{l}\text { Age group } \\
\text { (in years) }\end{array}$ & $\begin{array}{l}\text { All polyethylene } \\
\text { N }(\%)\end{array}$ & $\begin{array}{l}\text { Metal backed } \\
\mathbf{N}(\%)\end{array}$ \\
\hline $\mathbf{4 1 - 5 0}$ & $01(5.2)$ & $02(6.2)$ \\
\hline $\mathbf{5 1 - 6 0}$ & $06(20.9)$ & $11(34.3)$ \\
\hline More than 60 & $22(75.8)$ & $19(59.37)$ \\
\hline Total & $29(100)$ & $32(100)$ \\
\hline
\end{tabular}

$\chi^{2}$ value $=1.88, \mathrm{df}=2, \mathrm{p}$ value $=0.390, \mathrm{NS}$.

About $51.7 \%$ of the patients in all polyethylene group were male and $53.1 \%$ of the patients in MB group were female.

About $34.4 \%$ of the patients in all polyethylene group were operated on right side at a time and about $25 \%$ of the patients in MB group were operated on both sides at a time.
Table 2: Distribution of the study group according to sex.

\begin{tabular}{|lll|}
\hline Sex & $\begin{array}{l}\text { All } \\
\text { polyethylene } \\
\text { N }(\%)\end{array}$ & $\begin{array}{l}\text { Metal } \\
\text { backed } \\
\text { N }(\%)\end{array}$ \\
\hline Male & $15(51.7)$ & $15(46.8)$ \\
\hline Female & $14(48.3)$ & $17(53.1)$ \\
\hline Total & $29(100)$ & $32(100)$ \\
\hline
\end{tabular}

$\chi^{2}$ value $=0.17, \mathrm{df}=1, \mathrm{p}$ value $=0.67$, NS.

Table 3: Distribution of patients according to side operated at a time.

\begin{tabular}{|lll|}
\hline $\begin{array}{l}\text { Patient treated } \\
\text { with side at a time }\end{array}$ & $\begin{array}{l}\text { All } \\
\text { polyethylene } \\
\mathbf{N}(\%)\end{array}$ & $\begin{array}{l}\text { Metal } \\
\text { backed } \\
\mathbf{N}(\%)\end{array}$ \\
\hline Unilateral left & $8(27.5)$ & $13(40.6)$ \\
\hline Unilateral right & $10(34.4)$ & $11(34.3)$ \\
\hline Bilateral & $11(37.9)$ & $8(25)$ \\
\hline Total & $29(100)$ & $32(100)$ \\
\hline
\end{tabular}

$\chi 2$ value $=1.57, \mathrm{df}=2, \mathrm{p}$ value $=0.45$, NS.

Table 4: Distribution of the study group according to comorbid condition.

\begin{tabular}{|c|c|c|}
\hline Comorbid condition & $\begin{array}{l}\text { All } \\
\text { polyethylene } \\
\text { N }(\%)\end{array}$ & $\begin{array}{l}\text { Metal } \\
\text { backed } \\
\text { N }(\%)\end{array}$ \\
\hline Diabetes & $7(24.1)$ & $3(9.3)$ \\
\hline $\begin{array}{l}\text { Diabetes and } \\
\text { hypothyroid }\end{array}$ & $0(00)$ & $1(3.1)$ \\
\hline Hypertension & $9(31.03)$ & $11(34.3)$ \\
\hline $\begin{array}{l}\text { Hypertension, } \\
\text { asthma and } \\
\text { prostate }\end{array}$ & $0(00)$ & $1(3.1)$ \\
\hline $\begin{array}{l}\text { Hypertension and } \\
\text { diabetes }\end{array}$ & $2(6.89)$ & $2(6.2)$ \\
\hline $\begin{array}{l}\text { Hypertension and } \\
\text { prostate }\end{array}$ & $1(3.4)$ & $0(00)$ \\
\hline $\begin{array}{l}\text { Hypertension and } \\
\text { hypothyroid }\end{array}$ & $1(3.4)$ & $0(00)$ \\
\hline $\begin{array}{l}\text { Varicose vein and } \\
\text { bronchiectasis }\end{array}$ & 0 & $1(3.1)$ \\
\hline Nil & $9(31.03)$ & $13(40.06)$ \\
\hline Total & $29(100)$ & $32(100)$ \\
\hline
\end{tabular}

About $31.03 \%$ of the patients in all polyethylene group were having hypertension and $40.06 \%$ of the patients in MB group were not having any co-morbidities.

The mean $( \pm \mathrm{SD})$ of the flexion deformity was 19.0 $(0 \pm 12.82)$ in all polyethylene group and $17.44( \pm 9.69)$ in MB group which was not statistically significant.

Knee functional score pre-operative, after 1 month, after 3 months, after 6 months was not statistically significant.

Knee clinical score after 1 month, after 3 months, after 6 months was statistically significant. 
Table 5: Distribution of the study group according to flexion deformity.

\begin{tabular}{|lllll|}
\hline Flexion deformity & All polyethylene & Metal backed & $\mathbf{t}$ value & P value, sig \\
\hline Mean \pm SD & $19.0 \pm 12.82$ & $17.44 \pm 9.69$ & 0.635 & 0.527, NS \\
\hline
\end{tabular}

Table 6: Distribution of the study group according to knee function score.

\begin{tabular}{|lllll|}
\hline Parameter & $\begin{array}{l}\text { Pre-operative } \\
(\mathbf{m}-a n \pm \text { SD) }\end{array}$ & $\begin{array}{l}\mathbf{1}^{\text {st }} \text { month } \\
(\text { mean } \pm \text { SD })\end{array}$ & $\begin{array}{l}\mathbf{3}^{\text {rd }} \text { month } \\
(\text { mean } \pm \text { SD) }\end{array}$ & $\begin{array}{l}\mathbf{6}^{\text {th }} \text { month } \\
(\text { mean } \pm \text { SD })\end{array}$ \\
\hline All-poly & $40.92 \pm 2.39$ & $83.0 \pm 2.89$ & $85.05 \pm 2.74$ & $86.95 \pm 2.65$ \\
\hline Metal backed & $41.2 \pm 2.51$ & $83.6 \pm 2.27$ & $85.67 \pm 2.45$ & $87.29 \pm 2.31$ \\
\hline t value & 0.474 & 1.07 & 1.097 & 0.63 \\
\hline P value & $0.637, \mathrm{NS}$ & $0.288, \mathrm{NS}$ & $0.276, \mathrm{NS}$ & $0.531, \mathrm{NS}$ \\
\hline
\end{tabular}

Table 7: Distribution of the study group according to knee clinical score.

\begin{tabular}{|c|c|c|c|c|}
\hline Parameter & $\begin{array}{l}\text { Pre-operative } \\
(m e a n \pm \text { SD) }\end{array}$ & $\begin{array}{l}1^{\text {st }} \text { month } \\
(\text { mean } \pm \text { SD })\end{array}$ & $\begin{array}{l}\mathbf{3}^{\text {rd }} \text { month } \\
(\text { mean } \pm \text { SD })\end{array}$ & $\begin{array}{l}6^{\text {th }} \text { month } \\
(\text { mean } \pm \text { SD })\end{array}$ \\
\hline All- poly & $23.5 \pm 4.62$ & $84.55 \pm 2.7$ & $86.15 \pm 2.61$ & $87.47 \pm 2.56$ \\
\hline Metal backed & $23.4 \pm 4.44$ & $85.8 \pm 2.54$ & $87.7 \pm 2.71$ & $88.73 \pm 2.81$ \\
\hline t value & 0.102 & 2.022 & 2.777 & 2.149 \\
\hline P value & $0.919, \mathrm{NS}$ & 0.046, SIG & 0.007, SIG & 0.035, SIG \\
\hline
\end{tabular}

Table 8: Distribution of the study group according to range of motion.

\begin{tabular}{|lll|}
\hline Parameter & $\begin{array}{l}\text { Pre-operative } \\
(\text { mean } \pm \text { SD })\end{array}$ & $\begin{array}{l}\text { At } 6 \text { months } \\
(\text { mean } \pm \text { SD })\end{array}$ \\
\hline All- poly & $98.75 \pm 15.88$ & $125.0 \pm 14.68$ \\
\hline Metal backed & $98.0 \pm 17.14$ & $125.78 \pm 13.73$ \\
\hline t value & 0.208 & 0.252 \\
\hline P value & $0.835, \mathrm{NS}$ & $0.801, \mathrm{NS}$ \\
\hline
\end{tabular}

The improved knee range of motion after 6 months was not statistically significant.

\section{DISCUSSION}

This is a prospective study of 32 cases ( 40 knees) of newly diagnosed of primary OA knee cases treated with cemented TKR with Metal backed prosthesis and 29 cases (40 knees) with all polyethylene prosthesis. The patients were subjected for a detailed clinical examination. All the patients were assessed clinically and functionally using knee society score. All the patients were subjected for preoperative medical evaluation to prevent the complications that can be life threatening or limb threatening.

\section{Age}

The mean age of patients in our study was 62.03 years in all poly and 60.38 years in MB group. With youngest patient is being 50 years old and the oldest is being 82 years in all poly, 50 years old youngest patient and oldest being 65 years old in MB. In a study by Shen et al, the mean age of the all polyethylene group was 62.03 years and metal backed group was 60.38 years. ${ }^{6}$ In a study by Hydahl et al, the mean of all poly group was 73 years and
78 years in metal backed group. ${ }^{8}$ Senthilanathan also noted that majority of the patients were aged more than 60 years. ${ }^{9}$ In a study by Hamersveld et al, the mean age of all polyethylene group was 69 years and 68 years in metal backed group. ${ }^{10}$

\section{Sex}

Males outnumbered females in our study which was not statistically significant. In a study by Senthilanathan et al, there were equal number of males and females. ${ }^{9}$ In a study by Hamersveld et al, there were 22 females in all poly group and 13 in metal backed group. ${ }^{1}$

\section{Side operated at a time}

About $37.9 \%$ of the cases in all polyethylene group were operated bilaterally and $40.6 \%$ of the metal backed group had surgery on left side in 29 cases in all polyethylene group and 32 cases in metal backed group respectively. In a study by Senthilanathan et al, most of the patients were operated on right side. ${ }^{9}$

\section{Comorbid condition}

Hypertension was found was common comorbidity in $31.03 \%$ of the all polyethylene group and $34.3 \%$ of the metal backed group. It was followed by diabetes, hypothyroidism, asthma, prostate disease, varicose vein and bronchiectasis. The studies were not available to compare these results.

\section{Flexion deformity}

The mean flexion deformity score was 19 among the all polyethylene group and 17.44 among the metal backed 
group which not statistically significant between the two groups. No studies were available to compare these results. A study by Hyldahl et al, the deformity was more than $10^{\circ}$ in 1 patient all poly group. ${ }^{8}$

\section{Knee function score}

Before surgery, mean knee function score (KFS) was 40.92 in the all polyethylene group and 41.2 in the metal backed group which was not statistically significant. After 6 months, the mean KFS at 6 months was 86.95 in the all polyethylene group and 87.29 in the metal backed group which was statistically not significant. In a study by Senthilanathan et al, majority of the patients had excellent results. ${ }^{9}$ In a study by Hamersveld et al, after 2 years follow up most of the patients had excellent scores in all poly group. ${ }^{10}$

\section{Knee clinical score}

The mean pre-operative knee clinical score was 23.5 in poly ethylene group and 23.4 in metal backed group which was not statistically significant. After 1 month, the score increased to 84.65 in polyethylene group and 85.8 in metal backed group which was statistically significant. After 3 months, the score increased to 86.15 in polyethylene group and 87.7 in metal backed group which was statistically significant. After 6 months, the score increased to 87.47 in polyethylene group and 88.73 in metal backed group which was statistically significant. In a study by Van Hamersveld et al, the knee clinical score had shown improvements over time between the groups. But the patients with metal backed prosthesis suffered with complications. $^{10}$

\section{Range of motion}

Mean pre-operative range of motion score among the all polyethylene group was 98.75 and, in the metal, backed group was 98 which was not statistically significant. The score increased to 125 in the all polyethylene group and 125.78 in the metal backed group which was not statistically significant between the two groups. In a study by Sancheti et al, the mean preoperative range of motion improved at final follow up in the study group. ${ }^{11}$

\section{Pain score}

Pain is the most common indication for total knee replacement surgery. $98 \%$ patients of metal back and $97 \%$ of all poly total knee replacement showed improvement in pain. And $87 \%$ patients of metal back total knee replacement and $85 \%$ of all poly total knee replacement had no pain or just mild pain.

\section{Complication}

There were no cases of intraoperative and postoperative complications. There were no cases of osteolysis and synovitis in either group study. There were no cases of fixation failure in either group.

\section{CONCLUSION}

This study had shown that majority of patients undergoing knee replacement surgery are aged above 60 years, male sex and had comorbid conditions. There is statistically significant difference in clinical outcome between all polyethylene and metal backed, improved values in terms of pain, stability and range of motion in knee clinical score preferably in metal backed group than all polyethylene group. There is no statistically significant difference in functional outcome between all polyethylene and metal backed. But still superiority of metal backed tibial component in question. This study is not without limitations. Even though it is prospective study, patients were followed for shorter duration only. Hence, a study with elegant methodology and long follow up period can accurately assess the efficacy of all polyethylene and metal backed prosthesis used in knee replacement surgery.

\section{Funding: No funding sources}

Conflict of interest: None declared

Ethical approval: The study was approved by the institutional ethical committee

\section{REFERENCES}

1. Buckwalter JA, Mankin HJ. Articular cartilage: degeneration and osteoarthritis, repair, regeneration, and transplantation. Instr Course Lect. 1998;47:487504.

2. Zhang Y, Jordan JM. Epidemiology of osteoarthritis. Clin Geriatr Med. 2010;26:355-69.

3. Altman RD. Early management of osteoarthritis. Am J Manag Care. 2010;16:41-7.

4. Kadam RV, Yadav S, Chhallani A, Sharma C. Prospective study of clinical and functional outcome of total knee replacement in osteoarthritic knee. Int J Res Orthop. 2016;2:240-4.

5. Vince KG, Insall JN, Kelly MA. The total condylar prosthesis. 10 to 12 years results of a cemented knee replacement. J Bone Joint Surg Br. 1989;71:793-7.

6. Shen B, Yang J, Zhou Z, Kang P, Wang L, Pei F. Survivorship comparison of all-polyethylene and metal-backed tibial components in cruciatesubstituting total knee arthroplasty - Chinese experience. Int Orthop. 2009;33:1243-7.

7. Cormack MK, Cody JD, Murray D, Ramsay C, Campbell MK. Metal versus non-metal backing of the tibial component for total knee replacement for osteoarthritis and/or rheumatoid arthritis. Cochrane Database of Systematic Reviews. 2003;4:CD004801.

8. Hyldahl H, Regner L, Carlsson L, Karrholm J, Weidenhielm L. All-polyethylene vs. metal-backed tibial component in total knee arthroplasty: a randomized RSA study comparing early fixation of horizontally and completely cemented tibial components: Part 2, Completely cemented 
components: $\mathrm{MB}$ not superior to AP components. Acta Orthopaedica. 2005;76(6):778-84.

9. Senthilnathan A, Prabhakar R, Piriyan TP. Functional outcome of patients with osteoarthrosis of knee in south Indian population treated with total knee arthroplasty using all polyethylene tibial component: a prospective analysis. IJOS. 2018;4(3):652-9.

10. Hamersveld VKT, Van MD, Mheen PJ, Nelissen RGHH, Larsen TS. Migration of all-polyethylene compared with metal-backed tibial components in cemented total knee arthroplasty. Acta Orthopaedica. 2018;89(4):412-7.
11. Sancheti KH, Sancheti PK, Joshi RS, Patil KR, Shyam AK, Bhaskar RR. Mid-term survivorship and clinical outcome of INDUS knee prosthesis: 5 years follow up study. Indian J Orthop. 2016;50:131-5.

Cite this article as: Kriplani S, Patil T, Kulkarni M, Kulkarni GS, Kabra K, Parikh Y. Clinical and functional outcome of metal backed versus all polyethylene post operated total knee replacement patients: a prospective study. Int J Res Orthop 2020;6:748-53. 